\title{
The repaired tetralogy of Fallot become adult: what should we expect
}

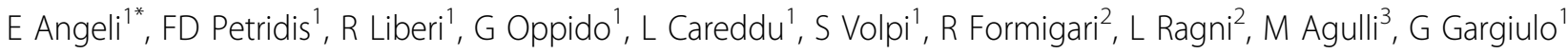 \\ From 23rd World Congress of the World Society of Cardio-Thoracic Surgeons \\ Split, Croatia. 12-15 September 2013
}

\section{Background}

To define the evolution of repaired Tetralogy of Fallot (TOF) in adult patients.

\section{Methods}

82 patients with repaired tetralogy of Fallot were collected from the database of our pediatric and congenital adult cardiology and cardiac surgery unit. Only patients older than 16 years of age at the time of the study were selected. All patients underwent complete surgical repair during childhood at a mean age of $1.6 \pm 1.3$ years. Forty-nine patients $(71.9 \%)$ were treated with transannular patch, 17(23.2\%) infundibular patch, 3(3.65\%) endoventricular repair and $1(1.2 \%)$ with conduit between the right ventricle(RV) and the pulmonary artery(PA); 17/82(20.7\%) of all patients required palliative BT shunt at birth before repair. Mean age at follow up was $23.7 \pm 6.7$ years. Follow-up schedule comprised clinical evaluation along with echocardiographic and cardiac-MR, quality of life and VO2 consumption assessment.

\section{Results}

After the 16 years of age, 53/82pts (65\%) didn't require any surgical procedure, 29/82(35\%) required reinterventions to reconstruct the right ventricle outflow tract. Associated residual VSD repair was performed in $1 / 29$ pts, tricuspid valve repair in $2 / 29$ and aortic valve repair in $1 / 29$. Twenty-one patients $(25.6 \%)$ required percutaneous procedures on pulmonary arteries, including pulmonary branch angioplasty in $11 / 21$, pulmonary stent implantation in $8 / 21$, percutaneous valve angioplasty in $2 / 21$. All patients survived. None of patients developed ventricular failure. At cardiopulmonary exercise testing the peak $\mathrm{VO} 2$ was moderately impaired.

Mean follow up time was $7.8 \pm 6.6$ years.

\section{Conclusion}

Survival prospects for adults with repaired TOF in adult age are now excellent. Incidence of reinterventions is predominant on the right ventricle outflow tract, where timing and correct indications are mandatory to avoid heart failure development. Late functional health status is satisfactory and quality of life is nearly comparable with those of healthy patients.

\section{Authors' details}

${ }^{1}$ Pediatric and Adult Congenital Cardiac Surgery Unit, S. Orsola-Malpighi Hospital, University of Bologna Medical School, Bologna, Italy. ${ }^{2}$ Pediatric and Adult Congenital Cardiology Unit, S. Orsola-Malpighi Hospital, University of Bologna Medical School, Bologna, Italy. ${ }^{3}$ Cardiosurgery Intensive Care Unit, S. Orsola-Malpighi Hospital, University of Bologna Medical School, Bologna, Italy.

Published: 11 September 2013

doi:10.1186/1749-8090-8-S1-0132

Cite this article as: Angeli et al:: The repaired tetralogy of Fallot become adult: what should we expect. Journal of Cardiothoracic Surgery 20138 (Suppl 1):0132.

\footnotetext{
* Correspondence: emanuela.angeli3@unibo.it

'Pediatric and Adult Congenital Cardiac Surgery Unit, S. Orsola-Malpighi

Hospital, University of Bologna Medical School, Bologna, Italy

Full list of author information is available at the end of the article
}

(c) 2013 Angeli et al; licensee BioMed Central Ltd. This is an Open Access article distributed under the terms of the Creative Commons 